\title{
IDIOSYNCRATIC RISK AND SPILLOVER EFFECT IN REIT RETURNS
}

\author{
Eddie C. M. HUI ${ }^{1}$, Ziyou WANG ${ }^{2, *}$ \\ ${ }^{1}$ Department of Building and Real Estate, The Hong Kong Polytechnic University, Hong Kong, China \\ ${ }^{2}$ Department of Land Economy, University of Cambridge, UK
}

Received 18 February 2016; accepted 9 October 2017

\begin{abstract}
Nowadays, idiosyncratic risk has substantial impacts on the risk control of portfolio construction. However, little research has been done on the spillover effect of idiosyncratic risk from global markets in REIT returns. A risk-return model is developed to examine the effects of idiosyncratic risk and its spillover on the short-run dynamics of REIT returns in 10 major REIT markets between 2001 and 2014. Variance decomposition provides evidence that idiosyncratic risk exceeds market risk most of the time. The risk-return models demonstrate that the spillover effect of idiosyncratic risk globally played a more significant role than idiosyncratic risk in the return dynamics during the subprime mortgage crisis. Furthermore, we analyse the asymmetric responses of volatility in REIT returns. The results show that the Netherlands is the most strongly preferred market in terms of earning excess returns, while the US market is unique in that the idiosyncratic risk and spillover effect tend to enlarge the fluctuations in REIT returns.
\end{abstract}

Keywords: asymmetric adjustment, idiosyncratic risk, risk-return model, spillover effect, variance decomposition.

\section{Introduction}

The primary means of short-term investment in the real estate market is to inject capital into either equities of real estate companies, or real estate investment trusts (REITs). Nowadays, REITs have developed into a substantial sector of the real estate market, as well as the stock market. The REIT market has drawn much attention as it provides a diversified and professional instrument in relation to the performance of the real estate market and enjoys a special tax status. The inclusion of REITs in investment portfolios can improve portfolio returns and/or reduce portfolio risk (Chen \& Peiser, 1999).

In theory, idiosyncratic risk is uncorrelated with aggregate market returns and hence can be mitigated through diversification. Diversification has been found to be effective in improving portfolio returns in the securitized property market (Worzala \& Sirmans, 2003). However, people find that idiosyncratic risk cannot be entirely removed by diversification in real markets, especially in the property market. Some evidence shows that idiosyncratic risk plays a significant role in explaining the excess risk premium (Liow \& Addae-Dapaah, 2010). Leverage and illiquidity, as important characteristics of real estate investment, are responsible for undiversifiable risk. Besides, a substantial number of investors complicate the situation by being under-diversified. They are either constrained by high transaction costs, holding constraints, or specific investment objectives (Xu \& Malkiel, 2003). Such situations have become more pronounced in the real estate and REIT markets. In this case, idiosyncratic risk can be a more important factor in estimating the return rate required by investors.

Although REITs can weaken leverage and illiquidity, idiosyncratic risk is still present at a high level for investors in the REIT market (Ooi, Webb, \& Wang, 2009). This can be attributed to several reasons. First, REITs are less sensitive to economic fluctuations (Sagalyn, 1990). As the real estate market is likely to be illiquid, real estate returns are not well justified by economic fundamentals. This is echoed by evidence provided in Eichholtz (1996), which shows that property returns have lower cross-country correlations than common stocks or bond returns. REITs have a close relationship with the direct property market in the long run (Stevenson, 2002) and thus REIT returns are prone to fluctuations (Chaudhry, Maheshwari, \& Webb, 2004). As such, idiosyncratic factors in real property held by REITs have a substantial effect on REIT returns. Second, securitized real estate is often under-diversified. Securitized real estate assets and property-related equities pursue the strategies of localisation and segmentation

*Corresponding author. E-mail: zywang30@gmail.com 
(Ooi et al., 2009) and REITs focus more on location or property type selection (Chiang, 2010). In this regard, REITs are more likely to construct a portfolio in a less-diversified way and thus require a higher return to compensate for the risks of less diversification. In addition, information incompleteness on the one hand is a critical factor for under-diversification of real estate investment, and on the other hand, it means that the prices cannot fully reflect market changes in time. As a result, REIT returns are susceptible to idiosyncratic risk. In the light of this, one of the purposes of this study is to examine whether idiosyncratic risk carries contributes more than systematic risk to the total volatility in global REIT markets. In particular, Pagliari, Scherer, and Monopoli (2003) find that REITs are always included in less diversified portfolios held by individuals or small institutional investors. The asset pricing implication of idiosyncratic risk from this study may serve as a reference for less diversified investors.

Securitized real estate markets are identified as comoving around the world. Also, securitized real estate is contagious to other real estate sectors and the stock market (Nneji, Brooks, \& Ward, 2013). Securities real estate markets not only show co-movement in terms of prices, but also display convergence in regard to volatility (Liow, Chen, \& Liu, 2011). Hence, idiosyncratic risk among the volatilities is supposed to spillover from a market to global markets through different channels. First, REITs as financial assets have been invested in by international investors and included in various portfolios (Hoesli \& Reka, 2013). The strategy of geographic diversification used by large REIT investors (Chaudhry et al., 2004) and applied in international portfolios enables the interflow of idiosyncratic risk. Another channel is the common equity market. Evidence has been reported of a link between securitized real estate and the stock market (e.g. Clayton \& MacKinnon, 2003). The integration of domestic and international stock markets provides a platform for the transmission of REIT idiosyncratic risk. In addition, direct real estate markets exhibit a growing connection, given the extent to which they are segmented (Case, Goetzmann, \& Rouwenhorst, 2000). Such connections establish an indirect channel for the spillover of REIT idiosyncratic risk. It is assumed that this channel may delay the spillover, as the direct real estate market incorporates information into prices slower than securitized real estate (Stevenson, 2002).

Unfortunately, whilst real estate studies on the correlations between market returns and volatilities have increased, it is still unclear how and to what extent a REIT market can be affected by spillovers of idiosyncratic risk in other markets. This paper attempts to examine the spillover effect of idiosyncratic risk in REIT returns to explore the material implications for asset pricing and make a contribution to the knowledge. In addition, many studies have revealed that idiosyncratic risk is a time-varying attribute in REIT markets along with financial fluctuations (Liow \& Addae-Dapaah, 2010). In general, the time-varying behaviour of volatility indicates the importance of the diversification of portfolio management at different stages of the business cycle. In particular, a clear exploration of volatility movement allows investors to better understand the level of diversification in their portfolio selection (Cotter \& Stevenson, 2006). Thus, it is imperative to explore both idiosyncratic risk and its spillover effect with time-varying features in modelling REIT returns.

The spillover of idiosyncratic risk in this study is measured by a proxy, namely integrated idiosyncratic volatility, introduced in Campbell, Lettau, Malkiel, and Xu (2001). The integrated idiosyncratic volatility represents a crossmarket integration of idiosyncratic risk. Following Campbell et al.'s (2001) approach, this paper intends to study the time-varying interactions among total, market and idiosyncratic risks. The appeal of the unconditional approach in Campbell et al. (2001) is that it avoids the estimation of the covariance or beta of the REIT markets in volatility decomposition.

Furthermore, this study attempts to establish a riskreturn model to investigate the dynamic correlation between REIT returns and idiosyncratic risk. By examining the spillover effect of idiosyncratic risk, this paper complements the study by Ooi et al. (2009), which shows the relevance of idiosyncratic risk in explaining monthly cross-sectional returns of REIT stocks. On the other hand, Martens and Poon (2001) found that the asymmetric response of equity return can be quite significant and have a large impact on the benefits of portfolio diversification. Michayluk, Wilson, and Zurbruegg (2006) verified the significance of asymmetries in both return and volatility movements in real estate securitized markets in the US and the UK. In this paper, our risk-return models are further developed to examine the existence of asymmetric responses of idiosyncratic risk and its spillovers to REIT returns.

Idiosyncratic risk is also related to price anomalies and bubbles in real estate markets. Bubbles, along with inflation over a certain period, can be reflected both in returns and volatility (Payne \& Waters, 2007). The price bubble, as an ex post concept, in real estate markets (or any other asset markets) can be identified only after the market has experienced a price recession. This implies that bubbles may exist in the real estate market anywhere and at any time. Although most securitized real estate markets experienced bubble crashes in 2008 (the Subprime Mortgage Crisis), each securitized property market has its own pattern of bubble development (Hui \& Wang, 2014), which suggests that idiosyncratic risk plays a significant role in both the performance and the development of bubbles in real estate securities. As a crisis always provides a platform for extreme fluctuations in return and volatility, it is necessary to cover the periods before and after 2008 crisis in this study, as more implications might be derived by comparing these two periods.

Our research objectives will be achieved in three steps: i) decomposing the total variance of REIT returns to demonstrate the movements of two components, i.e. market risk and integrated idiosyncratic variance; ii) establishing risk-return models to capture the dynamic correlations 
of idiosyncratic risk and its spillover with REIT returns; and iii) establishing an asymmetric model to analyse the asymmetric responses of volatility terms. The model implications may, in particular, serve to characterize the idiosyncratic risk and its spillover effect in explaining REIT returns, which might not only benefit investors and institutions in terms of understanding non-systematic risk and portfolio diversification, but might also assist related authorities in market monitoring and regulation-making.

The paper proceeds as follows. Section 1 presents the data and the sources. Section 2 introduces the research methods, including variance decomposition for risk analysis, risk-return models developed from GARCH-M mod$\mathrm{el}$, and asymmetric models based on risk-return models for asymmetry analysis. Section 3 discusses the empirical findings. Finally, the last section presents concluding remarks.

\section{Empirical data}

In this paper, ten markets are selected from among the global REIT markets: Australia, Belgium, Canada, France, Hong Kong, Japan, the Netherlands, Singapore, the UK and the US. In terms of REIT returns, these markets represent Asia, Europe and North America (Bond, Karolyi, \& Sanders, 2003). These markets contribute to the vast majority of the turnover and trading volume among global REIT markets (Liow, Ho, Ibrahim, \& Chen, 2009).

The data were extracted from the GPR 250 REIT index for each of the 10 markets from 2001 to 2014 and collected from the DataStream database. The index measures the total returns for each market in the local currency, which reflects the aggregate performance of the weighted components by assuming that all dividend distributions are reinvested, in addition to monitoring the price movements of components. This GPR REIT index is constructed to be a sustainable representation of the movements of global real estate securitized markets (Liow \& Ibrahim, 2010).

The daily returns are calculated by the first order difference of the natural logarithms for each market and their descriptive statistics are listed in panel A of Table 1. Due to the data availability, the series have different starting dates. All average returns are positive except for the UK. Hong Kong has the highest average $(0.078 \%)$, while the UK has a negative one $(-0.012 \%)$. The average return of a global market portfolio is $0.042 \%$, which is very close to the US return rate $(0.043 \%)$. The US shows the highest unconditional volatility (standard deviation, $2.001 \%$ ) followed by the UK (1.832\%). Asian REIT markets are characterized by higher volatility, compared to other developed markets. All of the return series present peaked distributions (i.e. kurtosis $>3$ ).

Table 1. Descriptive statistics of GPR 250 REIT index

\begin{tabular}{|c|c|c|c|c|c|c|c|c|}
\hline \multicolumn{9}{|c|}{ Panel A. Daily total return of GPR 250 REIT index (2001-2014) } \\
\hline & Starting year & Obs. & Mean & Max & Min & Std.dev. & Skewness & Kurtosis \\
\hline Australia & Jan.2001 & 3595 & 0.00024 & 0.07991 & -0.12151 & 0.01323 & -0.79 & 10.84 \\
\hline Belgium & Jan.2001 & 3600 & 0.00027 & 0.10316 & -0.07124 & 0.01052 & 0.28 & 7.89 \\
\hline Canada & Jan.2001 & 3601 & 0.00051 & 0.08680 & -0.08847 & 0.00952 & -0.71 & 12.20 \\
\hline France & Jan.2003 & 3086 & 0.00054 & 0.07155 & -0.08274 & 0.01446 & -0.09 & 3.40 \\
\hline Hong Kong & Oct.2004 & 2447 & 0.00078 & 0.13595 & -0.13571 & 0.01396 & -0.01 & 14.23 \\
\hline Japan & Oct.2001 & 3411 & 0.00034 & 0.1070 & -0.12149 & 0.01412 & -0.34 & 11.10 \\
\hline Netherlands & Jan.2001 & 3600 & 0.00034 & 0.07701 & -0.07519 & 0.01268 & -0.27 & 5.31 \\
\hline Singapore & Oct.2003 & 2900 & 0.00049 & 0.24765 & -0.22765 & 0.01475 & 0.35 & 50.59 \\
\hline UK & Jan.2007 & 2054 & -0.00012 & 0.09157 & -0.10786 & 0.01832 & -0.22 & 3.82 \\
\hline US & Jan.2001 & 3608 & 0.00043 & 0.17033 & -0.22050 & 0.02001 & -0.23 & 18.38 \\
\hline$r_{m}$ & Jan.2001 & 3610 & 0.00042 & 0.04989 & -0.06110 & 0.00796 & -0.90 & 10.04 \\
\hline \multicolumn{9}{|c|}{ Panel B. Weekly variance series (2001-2014) } \\
\hline & & Obs. & Mean & $\operatorname{Max}$ & Min & Std.dev. & Skewness & Kurtosis \\
\hline Australia & & 730 & 0.0007 & 0.0214 & 0.0000 & 0.0018 & 6.65 & 56.24 \\
\hline Belgium & & 730 & 0.0005 & 0.0158 & 0.0000 & 0.0010 & 8.36 & 103.27 \\
\hline Canada & & 730 & 0.0003 & 0.0158 & 0.0000 & 0.0009 & 9.75 & 138.35 \\
\hline France & & 626 & 0.0008 & 0.0144 & 0.0000 & 0.0013 & 4.45 & 29.02 \\
\hline Hong Kong & & 534 & 0.0007 & 0.0213 & 0.0000 & 0.0018 & 7.51 & 68.92 \\
\hline Japan & & 691 & 0.0008 & 0.0292 & 0.0000 & 0.0022 & 7.63 & 75.61 \\
\hline Netherlands & & 730 & 0.0006 & 0.0134 & 0.0000 & 0.0012 & 4.58 & 31.25 \\
\hline Singapore & & 587 & 0.0009 & 0.1134 & 0.0000 & 0.0049 & 21.22 & 486.54 \\
\hline UK & & 417 & 0.0013 & 0.0146 & 0.0000 & 0.0021 & 3.12 & 10.93 \\
\hline US & & 730 & 0.0017 & 0.0674 & 0.0000 & 0.0056 & 6.98 & 59.84 \\
\hline $\operatorname{Var}\left(R_{m}\right)$ & & 730 & 0.0002 & 0.0069 & 0.0000 & 0.0006 & 6.65 & 56.23 \\
\hline Firm-specific & & 730 & 0.0005 & 0.0131 & 0.0000 & 0.0011 & 6.68 & 61.11 \\
\hline
\end{tabular}


Weekly variance series can be calculated by using daily data. ${ }^{1}$ Panel B in Table 1 shows descriptive statistics for three types of sample variance. Consistent with Panel A, the US features the highest average of return variance (0.0017) followed by the UK (0.0013) again. All of the variance series display peaked distributions.

\section{Research methods}

The methods used in this study combine variance decomposition and risk-return models. Variance decomposition (Campbell et al., 2001) separates the total variance of asset return into two components: market variance and integrated idiosyncratic variance. The latter represents the average of all of the assets' idiosyncratic risks in a portfolio. In this study, the integrated idiosyncratic variance is employed to capture the spillover of idiosyncratic risks in other REIT markets on a market return.

Furthermore, a risk-return model is developed to examine the relationships between REIT returns and conditional risks. Empirical asset pricing models assume a significant correlation between the expected returns of an asset portfolio and its volatility in the short term. The GARCH in mean (GARCH-M) model is often regarded as an effective tool to describe such a risk-return relationship (Hung \& Glascock, 2010). This study develops a risk-return model from the GARCH-M model. Additionally, an asymmetric model derived from the standard risk-return model is designed to investigate the asymmetric responses of volatilities to return. The asymmetric model can reveal the difference in the roles of volatility in two opposite directions of return movement.

\subsection{Variance decomposition}

The use of variance decomposition (Campbell et al., 2001) in this study has two merits: first, it avoids the eimation obetas, and second, it omits the covariance term for individual equity in the variance decomposition.

Assume a market portfolio consists of 10 global REIT markets as selected in this study. Following the framework in Campbell et al. (2001), $w_{i, t}$ denotes the weight of the $i$-th REIT market with its excess return (denoted by $r_{i, t}$ ) in the market portfolio. The market excess return is defined as $r_{m, t}=\sum_{i}\left(w_{i, t} r_{i, t}\right)$, given constraint $\sum_{i} w_{i, t}=1$. In a weighted portfolio, the beta coefficients $\left(\beta_{i}^{i}\right)$ in the CAPM model can be summed to unity, i.e. $\sum_{i}\left(w_{i, t} \beta_{i}\right)=1$. The simplified CAPM model for the $i$-th REIT market is shown as:

$$
r_{i, t}=\beta_{i} r_{m, t}+\epsilon_{i, t},
$$

where: $\epsilon_{i, t}$ is the traditional residual orthogonal to the market portfolio return $r_{m, t}$. This ensures that different individual residuals are orthogonal to each other and the

1 The calculation method for weekly variance is introduced in section 2.1 . zero covariance between individual residual and market return. The variance in an individual market return can be expressed as:

$$
\operatorname{Var}\left(r_{i, t}\right)=\beta_{i}^{2} \operatorname{Var}\left(r_{m, t}\right)+\operatorname{Var}\left(\epsilon_{i, t}\right)
$$

Campbell et al. (2001) introduced a "market-adjustedreturn model", the benefit of which is that it avoids the estimation of betas. By applying this transformation, Eq. (1) can be expressed as:

$$
r_{i, t}=r_{m, t}+\tau_{i, t}
$$

where: $\tau_{i, t}$ denotes the market-adjusted idiosyncratic excess return. In this case, the relationship between $\tau_{i, t}$ and $\epsilon_{i, t}$ can be shown as follows:

$$
\tau_{i, t}=\epsilon_{i, t}+\left(\beta_{i}-1\right) r_{m, t} \text {. }
$$

Note that $\tau_{i, t}$ and $r_{m, t}$ are not orthogonal and thus the covariance between them cannot be neglected in the variance decomposition as $\operatorname{Cov}\left(r_{m, t}, \tau_{i, t}\right)=\left(\beta_{i}-1\right) \operatorname{Var}\left(r_{m, t}\right)$. Then the variance decomposition can also be presented as:

$$
\operatorname{Var}\left(r_{i, t}\right)=\operatorname{Var}\left(r_{m, t}\right)+\operatorname{Var}\left(\tau_{i, t}\right)+2 \operatorname{Cov}\left(r_{m, t}, \tau_{i, t}\right)
$$

and then re-write Eq. (5) as

$$
\operatorname{Var}\left(r_{i, t}\right)=\operatorname{Var}\left(\tau_{i, t}\right)+\left(2 \beta_{i}-1\right) \operatorname{Var}\left(r_{m, t}\right) \text {. }
$$

In this case, the covariance term is dismissed in Eq. (5'). Taking this advantage, the weighted total sum of variance consists of two parts:

$$
\begin{aligned}
& \sum_{i} w_{i, t} \operatorname{Var}\left(r_{i, t}\right)=\sum_{i} w_{i, t}\left(\operatorname{Var}\left(\tau_{i, t}\right)+\left(2 \beta_{i}-1\right) \operatorname{Var}\left(r_{m, t}\right)\right)= \\
& \sum_{i} w_{i, t} \operatorname{Var}\left(\tau_{i, t}\right)+\operatorname{Var}\left(r_{m, t}\right) .
\end{aligned}
$$

As suggested by Goyal and Santa Clara (2003), the market risk has no predicting power for the market return but average asset volatility has a positive relationship with market return. In this case, we extract the idiosyncratic variance from the total variance and put market risk aside. The sum of the weighted market-adjusted idiosyncratic variance (first term on the RHS, denoted by $V_{\tau}$ ) can be expressed as:

$$
V_{\tau}=\sum_{i} w_{i, t} \operatorname{Var}\left(\tau_{i, t}\right)=\sum_{i} w_{i, t} \operatorname{Var}\left(r_{i, t}\right)-\operatorname{Var}\left(r_{m, t}\right) .
$$

Equation (6') indicates that the sum of the weighted market-adjusted idiosyncratic variance is equal to the total weighted variance dispensed with market variance. For simplicity, all of the REIT markets are set with an equal weight in the portfolio and $V_{\tau}$ is renamed the integrated idiosyncratic risk. Henceforth, $V_{\tau}$ indicates the average spillover of the idiosyncratic risks across the portfolio.

For an empirical study using weekly data, an REIT market at week $t$, the weekly variances of the portfolio and each REIT market are calculated respectively by

$$
\operatorname{Var}\left(r_{m, t}\right)=\left(r_{m, t}-R_{m, t}\right)^{2} \text { and } \operatorname{Var}\left(r_{i, t}\right)=\left(r_{i, t}-R_{i, t}\right)^{2} \text {, }
$$

where: $R_{m, t}$ is the weekly sample mean of daily return $r_{m, t}$ and $R_{i, t}$ is the weekly sample mean of daily return $r_{i, t}$. 


\subsection{Idiosyncratic risk and its spillovers in mean}

For time-series data in modern financial markets, it is more reasonable to assume that the variations in asset returns have conditional distributions with a time varying feature rather than being constant (Bollerslev, 1986). Meanwhile, some financial studies show evidence that the short term dynamics of asset returns depend on volatilities among other things (Engle, Lilien, \& Robins, 1987). In recognizing this, asset pricing models try to incorporate volatility as an explanatory term in the return equation (Bali \& Peng, 2006). Recent studies, such as that of Hung and Glascock (2010), employ the GARCH-M model to improve the performance of the Fama-French three factor model by permitting risk to be time-variant and involved in the return equation. In the light of this, a risk-return model is developed to investigate the roles of idiosyncratic risk and its spillover effect in explaining the REIT market returns.

We start with a simple GARCH $(m, s)$-M model for an individual market,

$$
r_{i, t}=c_{i} h_{i, t}+u_{i, t} \text { and } u_{i, t}=\epsilon_{i, t} h_{i, t},
$$

where: $\epsilon_{i, t} \mid \Omega_{i, t-1} \sim N\left(0, h_{i, t}^{2}\right)$ and the GARCH part, implying that there are serial correlations between market return and the idiosyncratic volatility process $\left\{h_{i, t}\right\}$, is formed in an $\operatorname{ARMA}(m, s)$ process:

$$
h_{i, t}^{2}=a_{i, 0}+\sum_{j}^{m} a_{i, j} u_{i, t-j}^{2}+\sum_{j}^{s} b_{i, j} h_{i, t-j}^{2} .
$$

The formulation of a GARCH-M model such as that in Eqs (7)-(8) indicates that market return is adjusted by idiosyncratic volatility in the short term. Meanwhile, the idiosyncratic risk across the portfolio constitutes an integrated idiosyncratic risk, which reflects the aggregate of the spillover effect of the idiosyncratic risk from every market. Liow and Addae-Dapaah (2010) document that there exists a long-term relationship between such integrated idiosyncratic volatility and expected returns in the UIT markets. This study attempts to take a further step to examine the adjusting power of both the idiosyncratic and spillover effect (measured by integrated idiosyncratic risk) to REIT returns. By extending Eq. (7), a risk-turn model incorporating idiosyncratic risk and spillover effect can be expressed as

$$
r_{i, t}=c_{i} h_{i, t}+\sum_{k} g_{i, k} v_{t-k}+u_{i, t},
$$

where: $v=V_{\tau}^{0.5}$. The volatility equation of idiosyncratic risk would be the same as Eq. (8). In the above equation, process $\left\{h_{i, t}\right\}$ represents the expected idiosyncratic risk and pcess $\left\{v_{t}\right\}$ captures the spillover of idiosyncratic risk (proxied by integrated idiosyncratic risk). Eq. (9) implies tt there are serial correlations between the REIT market return and its idiosyncratic risk, as well as between the REIT return and the integrated idiosyncratic risk.

\subsection{Asymmetry in the model}

The analysis of asymmetry in the model reveals a pattern exhibiting asymmetric responses of volatility to the current return. The current return is manipulated by the different coefficients of two volatilities (denoted by $c_{i}^{d}$ and $\left.g_{i}^{d}\right)$ according to the state of lagged return at time $t-1$. As sh, the model can be extended to be associated with the asymmetric feature. In this case, the mean equation can be expressed as

$$
r_{i, t}=c_{i}^{d} \mathbf{1}^{d} h_{i, t}+\sum_{k} g_{i, k}^{d} \mathbf{1}^{d} v_{t-k}+u_{i, t},
$$

where: $c_{i}^{d}, g_{i, k}^{d} \sim \mathbf{1}^{d}\left(r_{i, t-1}\right)$ and $\mathbf{1}^{d}$ is the indicator function to select between two coefficients $c_{i}^{d}, d=1$ or 2 according to the sign of $r_{i, t-1}$.

The above equation indicates a conditional correlation between volatility and the REIT return. Since the volatility term is positive, a positive $c_{i}^{1}$ or $g_{i}^{1}$ implies a mean reversing effect on the previous negative return $\left(r_{i, t-1}<0\right)$ enforced by the volatility term. By contrast, a negative coefficient $c_{i}^{1}$ or $g_{i}^{1}$ implies a momentum effect accelerating the decline in return. On the other hand, aegative $c_{i}^{2}$ or $g_{i}^{2}$ indicates a momentum effect enforced by the volatility term to accelerate the rise, while a positive coefficient shows a mean reversing effect. A summary of these effects is as follows.

$$
\begin{gathered}
c_{i}^{1}, g_{i}^{1}\left\{\begin{array}{l}
<0, \text { mometumeffect on negative return } \\
>0, \text { mean reversing effect on negative return }
\end{array}\right. \\
c_{i}^{2}, g_{i}^{2}\left\{\begin{array}{l}
<0, \text { mean reversing effect on positive return } \\
>0, \text { mometumeffect on positive return }
\end{array}\right.
\end{gathered}
$$

Theoretically, a unit increase in idiosyncratic risk in a certain market should lead to a higher return to compensate for the risk premium, referring to the findings in Goyal and Santa-Clara (2003) and Fu (2009). To echo this, the coefficient $c_{i}^{1}$ is expected to be positive, as a positive coefficient indicates a mean reversing effect that helps in rebounding from the previous negative return. On the other hand, the spillover effect of idiosyncratic risk on other markets should pull the returns of other markets down and result in a depression on the average return of the portfolio (or global market). This can be echoed by a negative $g_{i}^{1}$, which indicates a momentum effect on negative return.

The asymmetry in the model can be rewritten in an alternative way (for simplicity, here only the first lagged term of the integrated idiosyncratic risk is retained):

$$
r_{i, t}=c h_{i, t}+g v_{t}+c_{i}^{\prime} \mathbf{1}_{\boldsymbol{r}} h_{i, t}+g_{i}^{\prime} \mathbf{1}_{\boldsymbol{r}} v_{t}+u_{i, t},
$$

where: $c_{i}^{\prime}$ and $g_{i}^{\prime}$ are regarded as two coefficients for the dummy variable $\mathbf{1}_{\boldsymbol{r}}=\mathbf{1}\left(r_{i, t-1}>0\right)$. These two coefficients (i.e. $c_{i}^{\prime}, g_{i}^{\prime}$ ) signify marginal adjustments to rurn rates in the situation of $r_{i, t-1}>0$. With a positive return at the previous time, a positive (negative) $c_{i}^{\prime}$ or $g_{i}^{\prime}$ indicates that one unit change in volatility can bring about a positive (negative) shock in addition to $t \mathrm{cnt}$ rurn. In other words, 
we can see that positive coefficients of $c_{i}^{\prime}, g_{i}^{\prime}$ constitute a driving force by which the vility term promotes a positive return rate and vice versa.

\section{Empirical study}

This section reports an empirical study. First, the empirical models are specified and the procedures of the model estimation are introduced. Then we present and discuss the empirical findings. Finally, the asymmetry analysis demonstrates the asymmetric patterns in which volatility responds to REIT returns.

\subsection{Empirical models}

Prior to the model construction, a few preliminary tests are applied to identify the characteristics of the data. All of the weekly return series are identified as being autocorrelated with lag 1 by using ARIMA model selection, and residual heteroscedasticity is confirmed by the Engle test (Engle, 1982) for all markets. The risk-return models are therefore specified with a lag-1 autoregressive term and heteroscedastic residual. Given the parameters of the model structure $\{m, s, k\}=\{1,1,1\}$, the mean equation of the empirical models thus becomes

$$
r_{i, t}=a_{i} r_{i, t-1}+c_{i} h_{i, t}+g_{i, k} v_{t-k}+u_{i, t} .
$$

The above risk-return model is designed to capture the short-run dynamics of REIT market returns. It incorporates an autoregressive term to depict short-run changes in market trend and volatility terms to portray the effects of idiosyncratic risk and the spillover of idiosyncratic risk.

The benchmark model can be considered a specific case of this risk-return model. That is, the risk-return model is reduced to a traditional GARCH-M model if $g_{i, k}=0$. The risk-return models and benchmark model can be estimated by maximum likelihood estimation (MLE). Meanwhile, the likelihood ratio test is employed simultaneously to identify the significance of the riskreturn model against the benchmark model in terms of testing the null hypothesis i.e. $g_{i, k}=0$.
Subsequently an asymmetry analysis based on the asymmetric model is used to detect asymmetry in the response of volatility to REIT returns, conditional on the lagged returns. The mean equation in the simplified model can be expressed as

$$
r_{i, t}=a_{i} r_{i, t-1}+c_{i}^{d} \mathbf{1}^{d} h_{i, t}+g_{i}^{d} \mathbf{1}^{d} v_{t}+u_{i, t},
$$

where: $c_{i}^{d}, g_{i, k}^{d} \sim \mathbf{1}^{d}\left(r_{i, t-1}\right)$ and $d=1,2$. Again, the asymmetric model can be estimated by MLE and the likelihood ratio test is used to identify the significance of the asymmetric model, in terms of the null hypothesis as $c_{i}^{d}=c$ and $g_{i}^{d}=g$. In addition, the asymmetry in the mod ce considered in an alternative way:

$$
r_{i, t}=a_{i} r_{i, t-1}+c h_{i, t}+g v_{t}+c_{i}^{\prime} \mathbf{1}_{\boldsymbol{r}} h_{i, t}+g_{i}^{\prime} \mathbf{1}_{\boldsymbol{r}} v_{t}+u_{i, t}
$$

where: $c_{i}^{\prime}, g_{i}^{\prime} \sim \mathbf{1}\left(r_{i, t-1}>0\right)$. Therefore, $c_{i}^{1}+c_{i}^{\prime}=c_{i}^{2}$ and $g_{i}^{1}+g_{i}^{\prime}=g_{i}^{2}$.

To reveal the dynamics of the correlation between returns and volatility over the study period, the model estimation is conducted by using a rolling estimation method in order to ensure robustness in the estimation results (see Bali \& Peng, 2006). The window of rolling estimation is fixed at 4 years (208 weeks) so that a sample series contains 208 observations. Thus the model at time $t$ offers implications for the subsequent three years (i.e. $[t, t+3 y]$ ).

\subsection{Variance decomposition}

Variance decomposition divides the total variance into two components, i.e. market variance $\operatorname{Var}\left(r_{m, t}\right)$ and integrated idiosyncratic variance $V_{\tau}$. Figure 1 plots the movements of these two components over the period 2001-2014. The integrated idiosyncratic variance plays a prominent le, as it contributes more of the total variance than market variance does for most of the study period. The ratio of the integrated idiosyncratic variance to the total variance, as plotted in Figure 1, fluctuates within the range of $30.8 \%$ to $99.4 \%$, with a mean of $75.09 \%$.

These two types of variance gradually increased from 2007; both variances reached their peak in 2008, and then

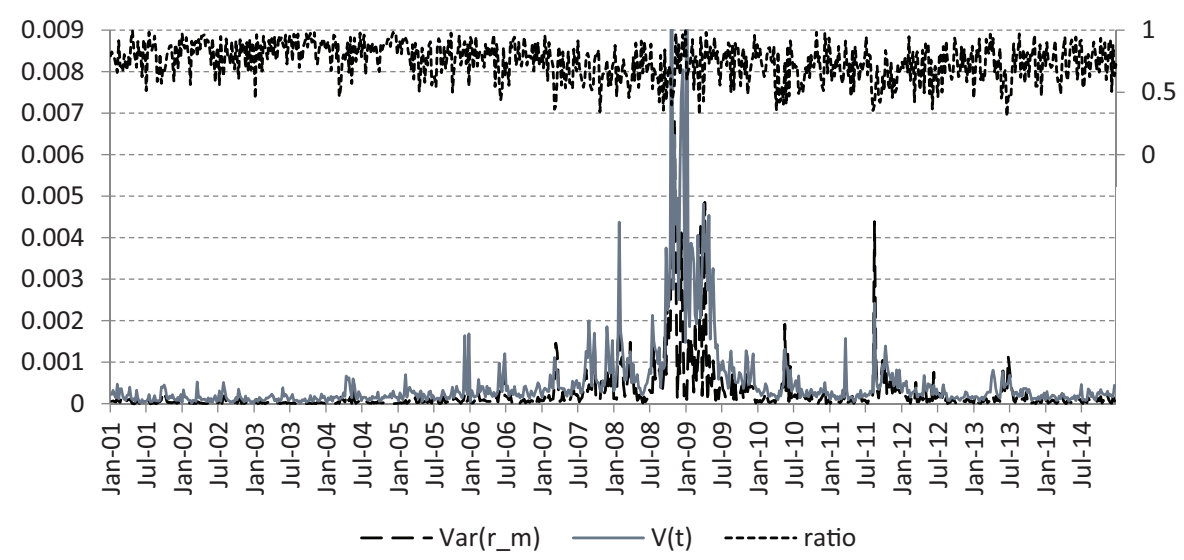

Figure 1. The decomposition of the total variance of Global REITs market into market variance and average firmspecific variance (left y-axis) as well as the ratio of firm-specific risk to total risk (right y-axis)

Note: $\mathrm{V}(\mathrm{t})$ denotes the average market-specific risk and $\operatorname{Var}\left(r \_\mathrm{m}\right)$ denotes the market risk. 
glided down after 2009. The crisis intensified the magnitudes of these two variances. It is, however, noteworthy that the peak of the integrated idiosyncratic risk (0.0131) is much higher than that of the market risk (0.0069). The average of the ratios of the integrated idiosyncratic variances to the total variance varied from $81.18 \%$ before 2007 , fell to $70.16 \%$ over the period $2007-2009$, and then settled at $70.32 \%$ after the crisis. This implies that market risk has risen in importance since the crisis. Our results are similar to the pattern of REIT volatility in the US market (see Liow \& Addae-Dapaah, 2010). As a matter of fact, the financial crisis started off in the US and spread across the world. It is quite conceivable that the movements of integrated idiosyncratic and total risks in the US REIT market were in tandem with those in global REIT markets.

\subsection{The relationship between return and risk}

Risk-return models offer detailed evidence to reveal the correlations between REIT returns and idiosyncratic risk, as well as the spillover of idiosyncratic risk. The likelihood ratio test explores the significance of the explanatory capacity of the spillover of idiosyncratic risk in the dynamics of REIT returns. It compares the performance of the risk-return models to that of the benchmark models (GARCH-M).
Panel A in Table 2 reports the descriptive summary of the statistics of the likelihood ratio test for the 10 markets. Rejection of the null hypothesis (the benchmark model is a sufficient model to fit the data) accounts for a minor proportion of the tests for all of the markets except Hong Kong and Singapore. There are no significant tests for the Hong Kong market, and the benchmark model dominates over the study period, indicating that the spillover effect of idiosyncratic risk from other markets insignificantly affects the REIT returns. By contrast, Singapore exhibits a high frequency (288/381) of significant statistics over the period. The spillover effect cannot be ignored in Singapore's REIT return pricing.

Figure 2 contains 10 sub-figures plotting the curve of test statistics for the 10 markets respectively. Each market has its own pattern of curve and there is no obvious comovement between the markets before 2007. In addition, these figures indicate that, as the subprime mortgage crisis (2007) spread around the world, the integrated idiosyncratic risk affected the REIT return to different degrees in all of the markets, except for Hong Kong. In other words, idiosyncratic risk spilled over to affect other markets through the integrated idiosyncratic risk during the crisis period.

Table 2. Descriptive statistics of the test statistics of likelihood ratio test for 10 REIT markets (weekly data)

\begin{tabular}{|c|c|c|c|c|c|c|}
\hline \multicolumn{7}{|c|}{ Panel A. Model selection between benchmark and risk-return models } \\
\hline & \#. of test & $\begin{array}{l}\text { \#. of significant } \\
\text { test statistics }\end{array}$ & Mean & Max & Min & Std.dev. \\
\hline Australia & 522 & 195 & 6.9503 & 22.0712 & -2.2765 & 6.1628 \\
\hline Belgium & 522 & 82 & 3.8601 & 15.2933 & 0.2465 & 3.7076 \\
\hline Canada & 522 & 111 & 4.4679 & 14.2955 & -2.1420 & 3.8760 \\
\hline France & 420 & 47 & 3.1088 & 11.8852 & -3.9086 & 3.4852 \\
\hline $\mathrm{HK}$ & 327 & 0 & 2.7028 & 7.2080 & -1.3399 & 1.2301 \\
\hline Japan & 485 & 174 & 6.3920 & 22.3234 & -0.5209 & 7.3059 \\
\hline Netherlands & 522 & 62 & 3.7768 & 18.0311 & -0.5514 & 3.9368 \\
\hline Singapore & 381 & 288 & 10.9933 & 20.0143 & 1.3568 & 3.7517 \\
\hline UK & 211 & 87 & 6.5964 & 18.8570 & 0.6229 & 4.5984 \\
\hline US & 522 & 86 & 4.2550 & 16.1627 & -3.6205 & 3.9914 \\
\hline \multicolumn{7}{|c|}{ Panel B. Model selection between standard and asymmetric type of risk-return models } \\
\hline & \#. of test & $\begin{array}{l}\text { \#. of significant } \\
\text { test statistics }\end{array}$ & Mean & Max & Min & Std.dev. \\
\hline Australia & 522 & 34 & 4.4233 & 15.3757 & 1.5004 & 2.7763 \\
\hline Belgium & 522 & 23 & 4.4657 & 12.4675 & 1.9644 & 2.1841 \\
\hline Canada & 522 & 97 & 6.1101 & 12.9636 & 0.9169 & 2.7381 \\
\hline France & 420 & 73 & 6.4651 & 14.4663 & 2.6191 & 2.7084 \\
\hline Hong Kong & 327 & 104 & 7.1573 & 17.4355 & 3.9765 & 3.0392 \\
\hline Japan & 485 & 198 & 8.0563 & 14.5699 & 2.6380 & 2.7319 \\
\hline Netherlands & 522 & 39 & 5.2726 & 16.4942 & 2.2889 & 2.3377 \\
\hline Singapore & 381 & 21 & 3.8603 & 11.3951 & 0.9777 & 2.1733 \\
\hline UK & 211 & 2 & 2.1494 & 9.0260 & 0.0031 & 1.8724 \\
\hline US & 522 & 151 & 5.8559 & 19.9135 & 0.0019 & 4.9953 \\
\hline
\end{tabular}

Note: $5 \%$ significant value $=8.64$ for likelihood tests in Panel A and 5\% significant value $=9.04$ for likelihood tests in Panel B. 


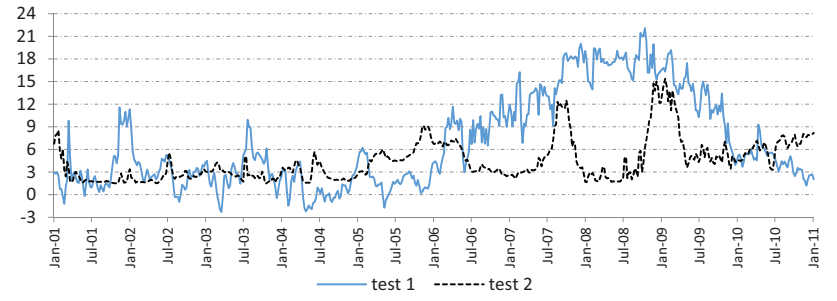

(a) Results of likelihood ratio test for Australia REIT market

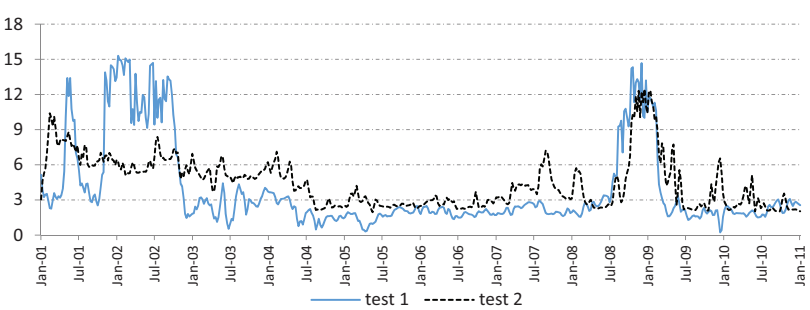

(b) Results of likelihood ratio test for Belgium REIT market

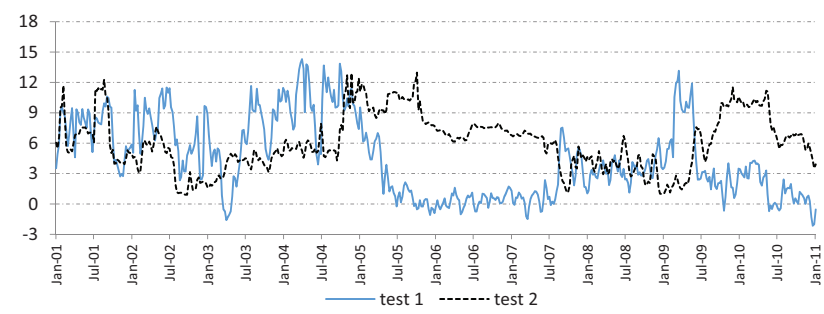

(c) Results of likelihood ratio test for Canada REIT market

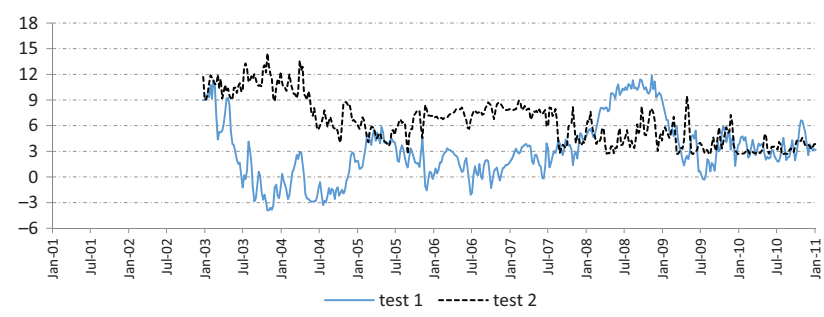

(d) Results of likelihood ratio test for France REIT market

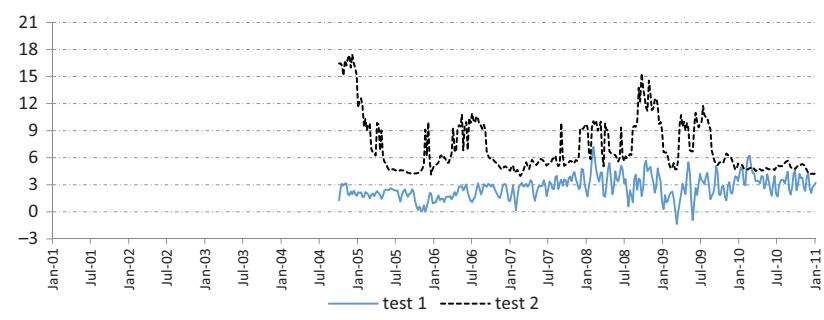

(e) Results of likelihood ratio test for Hong Kong REIT market

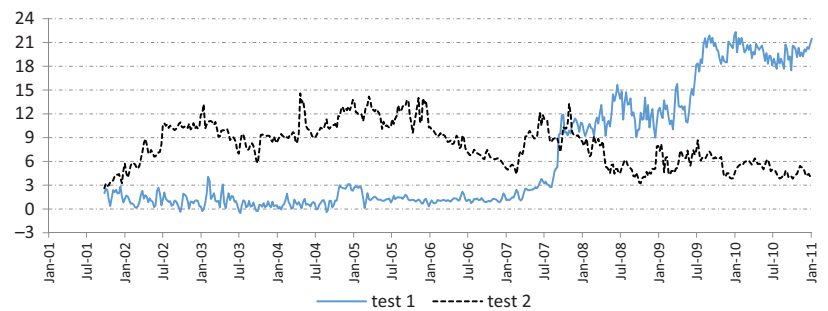

(f) Results of likelihood ratio test for Japan REIT market

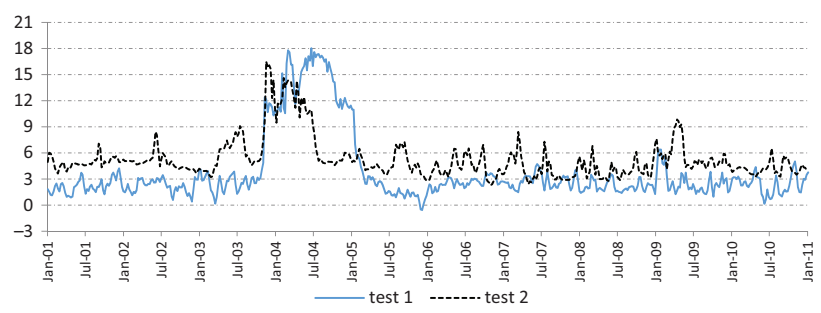

(g) Results of likelihood ratio test for Netherlands REIT market

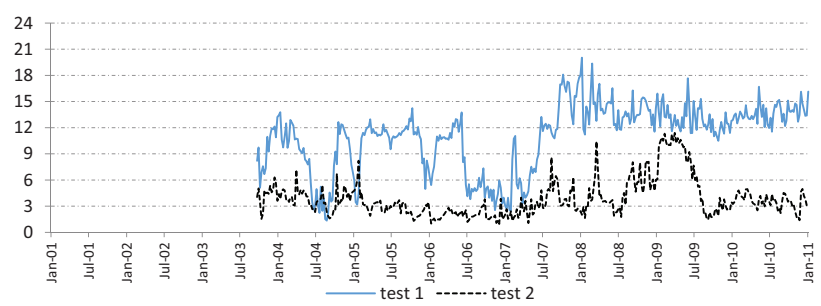

(h) Results of likelihood ratio test for Singapore REIT market

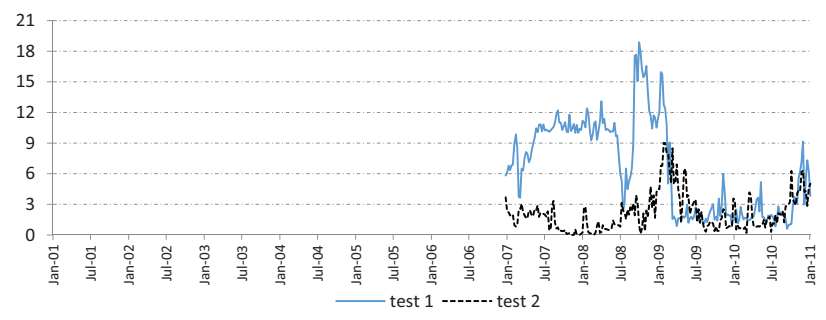

(i) Results of likelihood ratio test for the UK REIT market

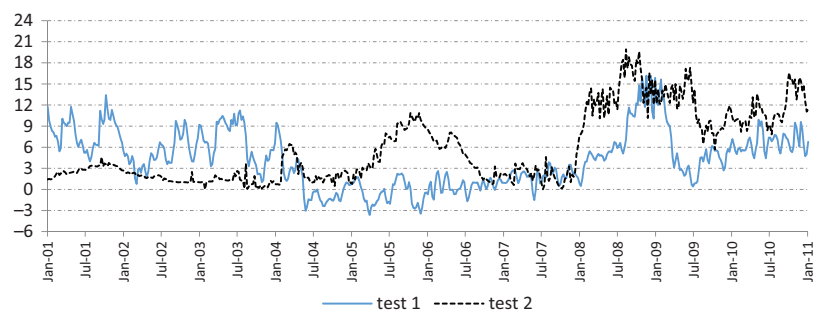

(j) Results of likelihood ratio test for the US REIT market

Figure 2. Results of likelihood ratio tests for 10 global REIT markets

Note: a) Test1 is to test the null hypothesis of GARCH-M model being better than spillover effect model to fit the data. b) Test2 is to test the null hypothesis of no asymmetry existing in spillover effect model. c) $5 \%$ significant level is 8.64 for likelihood testland $5 \%$ significant level is 9.04 for likelihood test 2 . 


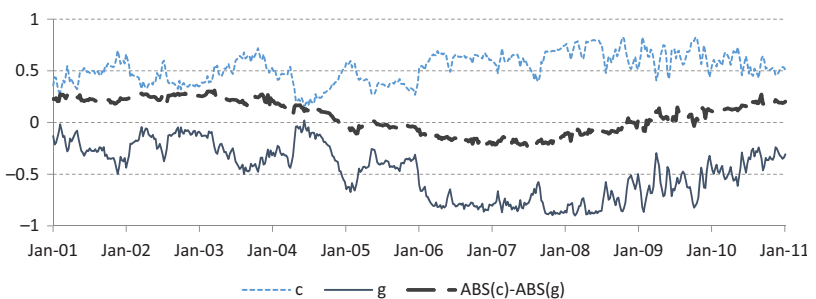

(a) Curves of estimated parameters in risk-return model for Australia REIT market

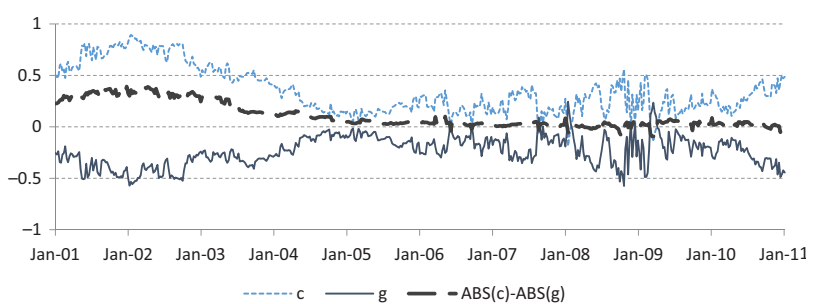

(b) Curves of estimated parameters in risk-return model for Belgium REIT market

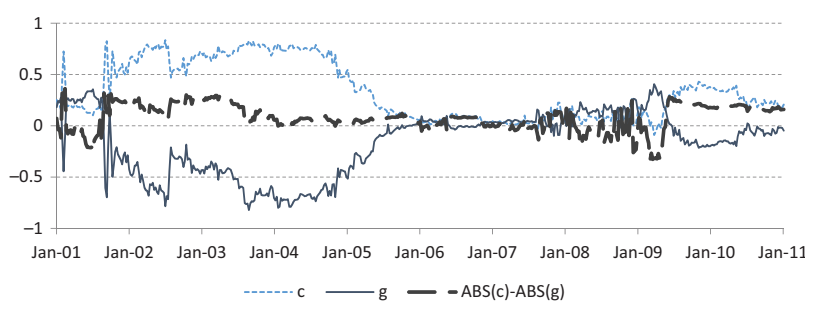

(c) Curves of estimated parameters in risk-return model for Canada REIT market

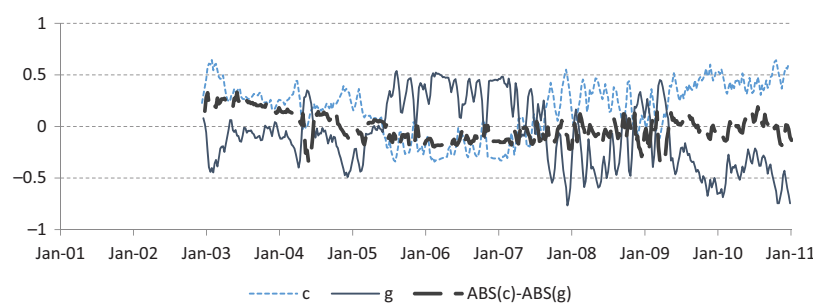

(d) Curves of estimated parameters in risk-return model for France REIT market

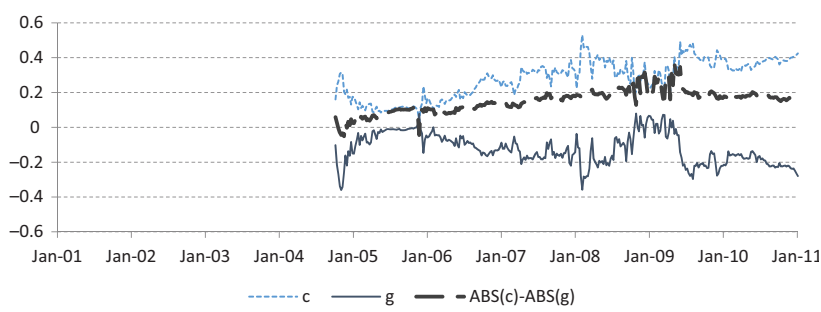

(e) Curves of estimated parameters in risk-return model for Hong Kong REIT market

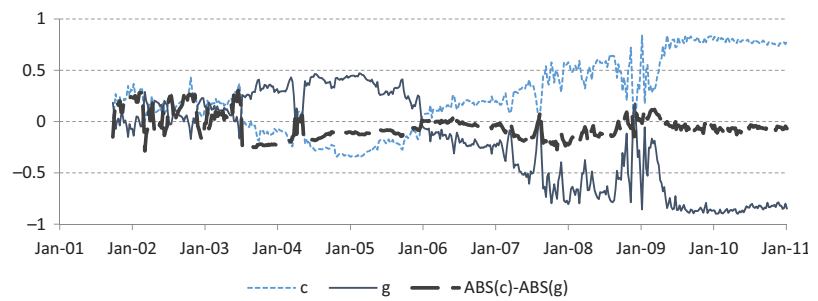

(f) Curves of estimated parameters in risk-return model for Japan REIT market

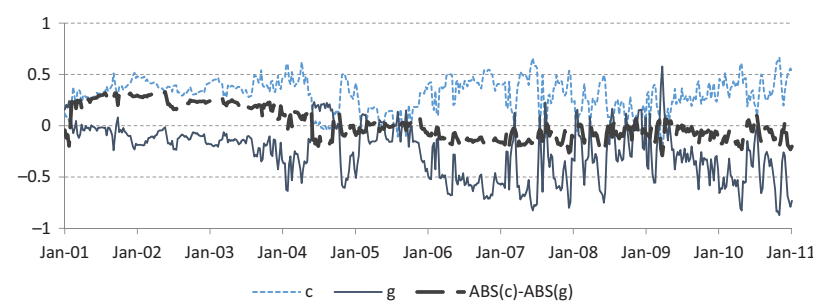

(g) Curves of estimated parameters in risk-return model for Netherlands REIT market

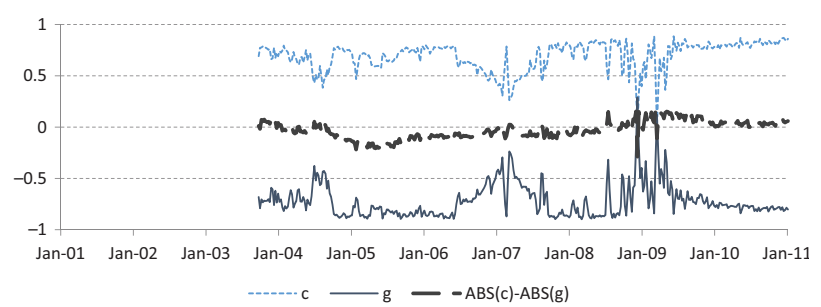

(h) Curves of estimated parameters in risk-return model for Singapore REIT market

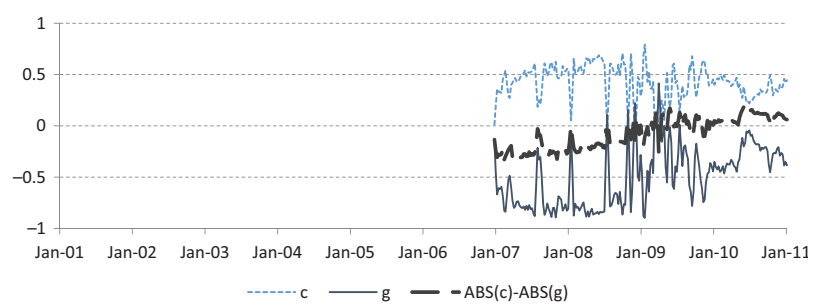

(i) Curves of estimated parameters in risk-return model for the UK REIT market

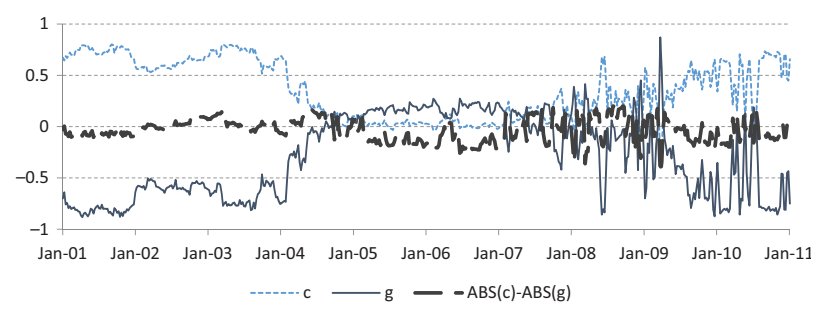

(j) Curves of estimated parameters in risk-return model for the US REIT market

Figure 3. Estimated parameters in risk-return model for 10 global REIT markets 
The spillover of idiosyncratic risk continues to exert an impact on the market return in Australia, Japan, Singapore and the UK. These four markets are typical representatives in which many REITs pursue a geographical diversification strategy. That is, these REITs invest not only in local markets but also in international markets, or even focus largely on international markets. These markets are therefore vulnerable to the spillover effect of idiosyncratic risk. Contrarily, in Hong Kong, REITs concentrate on the local market only and thus the spillover effect is trivial.

Figure 3 consists of 10 sub-figures, each of which displays three curves. The dotted line and the full line display the estimated coefficients $c$ and $g$ respectively. These two lines help to explain the role of idiosyncratic risk and the spillover effect in the dynamics of REIT market return. In general, the idiosyncratic risk always plays the opposite role to spillover effects in a certain market. This finding highlights the heterogeneous impacts of these two risks on REIT returns, which has practical implications for REIT market participants and policymakers. In addition, the thick dotted line captures the discrepancy between the two magnitudes (absolute values) of $c$ and $g$. A higher absolute value of the coefficient indicates that a unit change in the corresponding risk could cause a larger shock than the other one to the REIT return.

Figure 3 shows interesting yet complex results, which are partly attributable to the differences in the significance of the test statistics (see Figure 2). For instance, none of the test statistics is significant in the Hong Kong REIT market. Prior to 2006, idiosyncratic risk had stronger impacts than integrated idiosyncratic risk on market return in Australia, Belgium, Canada, France and the Netherlands. During the crisis period, the spillover of idiosyncratic risk provided more driving forces to the dynamics of REIT returns than idiosyncratic risk in many markets, namely Australia, Canada, France, Japan, the Netherlands, Singapore and the UK. This indicates that the crisis was aggravated not only by idiosyncratic risk itself, but also by the spillover of idiosyncratic risk from other markets, and it was contagious across the global market.

The US market shows a totally different situation since it was the major source of the crisis ${ }^{2}$. First, the discrepancy between the coefficients of the two risks fluctuated around zero during the crisis. It infers that the effects of idiosyncratic risk and of the spillover of idiosyncratic risk from other markets dominate the US market by turns. Furthermore, the signs of the coefficients of the two risks in the US REIT market reversed, implying that these two risks swapped roles in the dynamics of market return during the crisis. The idiosyncratic risk dragged the market and drove the recession while the spillover effect tried to slow the recession.

\footnotetext{
2 The US securitized property market al.ays plays a key role in the global market as an information producer and driving force, having great impacts on other markets' returns (see Liow et al., 2011).
}

After the subprime mortgage crisis (2009 onwards), idiosyncratic risk became dominant in Australia, Canada, Singapore and the UK. In these four markets, idiosyncratic risk showed a positive correlation with market return while spillover effects took on the opposite role to idiosyncratic risk.

A downward trend in the coefficient of idiosyncratic risk was found in the US market as well as in other markets (Belgium, Canada and Japan) before 2008. The finding regarding the US market is consistent with the findings in Liow and Addae-Dapaah (2010). Yet this study provides a new finding, which is that there was a rebound of this coefficient in the US market after 2008. Meanwhile, the magnitude of idiosyncratic risk exceeded that of the spillover of idiosyncratic risk.

\subsection{Asymmetry in models}

In terms of asset return and volatility, asymmetric adjustment has been observed in modern finance, which shows that return or volatility has significantly inconsistent impacts in asset pricing when responding to past events, especially during a crisis. In this section, we investigate whether there is an asymmetric response of the volatility term to returns, conditional on previous returns. This implies an additional adjustment of risk to return triggered by the regime switching of the market return. The implications could benefit market participants and policymakers, as they may serve as a reference for the REIT return mechanism.

Panel B in Table 2 reports the descriptive statistics of tests for the asymmetric model selection for the 10 markets. It shows that rejection of the null hypothesis (the standard risk-return model is a sufficient model) accounts for only a minor proportion of the tests for the 10 markets. In other words, the standard risk-return model fits the data series relatively well over the whole period. Japan holds the highest frequency (198/485) of significant statistics among the 10 markets. By contrast, the UK has only two significant statistics, ${ }^{3}$ and thus is excluded from the following discussion.

The dotted lines in Figure 2 illustrate the test statistics for the asymmetric models. Similarly, each of the 10 markets has its own patterns of test statistics that are different from the others. In each figure, the curves of the two tests are inconsistent in their trends. With regard to the riskreturn model, the asymmetric version fits the data better than the standard in Australia, Belgium, Hong Kong and the US during the crisis period. In comparison, the asymmetric model captures more accurately the dynamics of REIT returns ahead of the crisis in some markets. Canada, France, Hong Kong, Japan and the Netherlands

3 This may be because of the data limitation. The UK's data are available from January 2007, but for all other indices the data are available at least from October 2004. Hence the UK has the fewest observations among the 10 indices. With so few data points, there is a higher chance of obtaining extreme results. 
experienced asymmetry in the response of volatility more or less during the market boom. Of these five markets, Japan had the longest period of asymmetric response of volatility before the crisis and the market return was fuelled by the idiosyncratic risk. This is mainly due to the long recession that affected Japan's economy from 1990. Interestingly, the existence of asymmetry in volatility's response in the US market mainly began from 2010 rather than the crisis period.

Table 3 reports the descriptive statistics of the estimated coefficients in the asymmetric models. For all of the markets except for the US, $c_{i}^{1}$. is positive for most of the time periods in which the tests for asymmetry are significant. That is, idiosyncratic risk has a mean reversing effect on the current return if the previous return is negative. By contrast, for all of the markets, $g_{i}^{1}$. is negative for most of the time periods in which the tests for asymmetry are significant. This indicates that the spillover effect has a momentum effect on the current return if the previous return is negative. Hence, idiosyncratic risk in a certain market spills over to accelerate the decline in returns in other markets. The idiosyncratic and integrated idiosyncratic risks are wrestling if the previous return is negative for all of the markets, except for the US. These two implications are in line with the hypotheses in Section 2.
The coefficient $c_{i}^{2}$ shows different results. Australia, Belgium, Canada, the Netherlands, Singapore and the US have a positive $c_{i}^{2}$ for most of the time, while the rest have negative ones. France, Hong Kong, Japan, the Netherlands and the US have a positive $g_{i}^{2}$ for most of the time, while the rest have negative coefficients. Overall, as shown in Table 4, the nine markets (excluding the UK) can be categorized into four types with respect to asymmetric patterns. The asset pricing implications of this classification can benefit investors and policymakers.

Idiosyncratic risk is more likely to drive the market return to be positive in Type 1 and 2 markets and offers a mean reversing effect on the return in Type 3 markets. Thus, the behaviour patterns of idiosyncratic risk in Type 1 and 2 markets are consistent with the findings in Goyal and Santa-Clara (2003) and Fu (2009). On the other hand, the spillover effect is more likely to lead the market return to be negative in Type 2 markets and drives the market return away from zero in both directions in Type 1 and 3 markets. In addition, idiosyncratic risk exhibits asymmetric adjustments opposite to the spillover effect on mark return in Type 2 and 3 markets. Type 1 markets (the Netherlands only) are the most preferred of these three types in terms of acquiring excess returns in the periods with significant asymmetry, followed by Type 2 . The pos-

Table 3. Descriptive Statistics of the estimated parameters in asymmetric models for 10 REIT markets (weekly data)

\begin{tabular}{|c|c|c|c|c|c|c|c|c|c|c|c|c|}
\hline & $c^{1}$ & $c^{2}$ & $g^{1}$ & $g^{2}$ & $c^{\prime}$ & $g^{\prime}$ & $c^{1}$ & $c^{2}$ & $g^{1}$ & $g^{2}$ & $c^{\prime}$ & $g^{\prime}$ \\
\hline & \multicolumn{6}{|c|}{ Australia (34) } & \multicolumn{6}{|c|}{ Japan (198) } \\
\hline Mean & 0.46 & 0.64 & -0.60 & -0.62 & 0.18 & -0.02 & 0.35 & -0.11 & -0.47 & 0.42 & -0.46 & 0.89 \\
\hline Std & 0.25 & 0.25 & 0.29 & 0.31 & 0.44 & 0.47 & 0.27 & 0.34 & 0.25 & 0.32 & 0.37 & 0.34 \\
\hline$>0$ & 32 & 33 & 1 & 2 & 24 & 15 & 195 & 79 & 3 & 182 & 14 & 195 \\
\hline \multirow[t]{2}{*}{$<0$} & 2 & 1 & 33 & 32 & 10 & 19 & & 119 & 195 & 16 & 184 & 3 \\
\hline & \multicolumn{6}{|c|}{ Belgium (23) } & \multicolumn{6}{|c|}{ Netherlands (39) } \\
\hline Mean & 0.03 & 0.44 & 0.10 & -0.43 & 0.41 & -0.53 & 0.49 & 0.28 & -0.41 & -0.14 & -0.21 & 0.26 \\
\hline Std & 0.41 & 0.33 & 0.45 & 0.21 & 0.51 & 0.45 & 35 & 0.32 & 0.33 & 0.40 & 0.59 & 0.59 \\
\hline$>0$ & 14 & 22 & 10 & 1 & 19 & 1 & 35 & 30 & 7 & 20 & 14 & 25 \\
\hline \multirow[t]{2}{*}{$<0$} & 9 & 1 & 13 & 22 & 4 & 22 & 4 & 9 & 32 & 19 & 25 & 14 \\
\hline & \multicolumn{6}{|c|}{ Canada (97) } & \multicolumn{6}{|c|}{ Singapore (21) } \\
\hline Mean & 0.12 & 0.54 & -0.21 & -0.24 & 0.42 & -0.03 & 0.76 & 0.47 & -0.74 & -0.26 & -0.29 & 0.48 \\
\hline Std & 0.53 & 0.33 & 0.60 & 0.36 & 0.81 & 0.91 & 0.18 & 0.42 & 0.19 & 0.44 & 0.46 & 0.48 \\
\hline$>0$ & 63 & 93 & 34 & 36 & 60 & 63 & 21 & 19 & 0 & 3 & 5 & 19 \\
\hline \multirow[t]{2}{*}{$<0$} & 34 & 4 & 63 & 61 & 37 & 34 & 0 & 2 & 21 & 18 & 16 & 2 \\
\hline & \multicolumn{6}{|c|}{ France (73) } & \multicolumn{6}{|l|}{ UK (2) } \\
\hline Mean & 0.79 & -0.10 & -0.81 & 0.58 & -0.90 & 1.39 & 0.15 & 0.87 & -0.32 & -0.86 & 0.72 & -0.53 \\
\hline Std & 0.09 & 0.23 & 0.13 & 0.23 & 0.20 & 0.23 & 0.08 & 0.02 & 0.13 & 0.00 & 0.06 & 0.13 \\
\hline$>0$ & 73 & 26 & 0 & 72 & 0 & 73 & 2 & 2 & 0 & 0 & 2 & 0 \\
\hline \multirow[t]{2}{*}{$<0$} & 0 & 47 & 73 & 1 & 73 & 0 & 0 & 0 & 2 & 2 & 0 & 2 \\
\hline & \multicolumn{6}{|c|}{ Hong Kong (104) } & \multicolumn{6}{|c|}{ US (151) } \\
\hline Mean & 0.73 & -0.13 & -0.45 & 0.15 & -0.86 & 0.60 & -0.17 & 0.63 & -0.11 & -0.25 & 0.80 & -0.14 \\
\hline Std & 0.16 & 0.29 & 0.32 & 0.39 & 0.40 & 0.67 & 0.45 & 0.32 & 0.58 & 0.50 & 0.66 & 0.85 \\
\hline$>0$ & 104 & 35 & 10 & 68 & 2 & 81 & 68 & 137 & 65 & 35 & 129 & 80 \\
\hline$<0$ & 0 & 69 & 94 & 36 & 102 & 23 & 83 & 14 & 86 & 116 & 22 & 71 \\
\hline
\end{tabular}

Note: Number in ( ) indicates the number of significant statistics shown in Table 4. 
Table 4. The type of asymmetric patterns of two volatilities for 10 REIT markets

\begin{tabular}{|l|c|c|c|c|c|}
\hline \multicolumn{1}{|c|}{ Market } & $c^{2}$ & $g^{2}$ & $c^{\prime}$ & g' & type \\
\hline$c^{1}>0, g^{1}<0$ & $>0$ & $<0$ & $>0$ & $<0$ & 2 \\
\hline Australia & $>0$ & $<0$ & $>0$ & $<0$ & 2 \\
\hline Belgium & $>0$ & $<0$ & $>0$ & $>0$ & 2 \\
\hline Canada & $<0$ & $>0$ & $<0$ & $>0$ & 3 \\
\hline France & $<0$ & $>0$ & $<0$ & $>0$ & 3 \\
\hline Hong Kong & $<0$ & $>0$ & $<0$ & $>0$ & 3 \\
\hline Japan & $>0$ & $>0$ & $<0$ & $>0$ & 1 \\
\hline Netherlands & $>0$ & $<0$ & $<0$ & $>0$ & 2 \\
\hline Singapore & - & - & - & - & - \\
\hline UK ${ }^{\#}$ & \multicolumn{5}{|c|}{} \\
\hline$c^{1}<0, g^{1}<0$ & $>0$ & $>0$ & $>0$ & $>0$ & 4 \\
\hline US
\end{tabular}

Note: There are very few of significant statistics in the asymmetric model for UK, so UK is excluded.

sible reasons are that the Netherlands has a relatively low correlation with other markets and has been less affected by the crisis. Type 3 markets are characterized by lower return fluctuations, where higher volatilities could not lead to a higher risk premium, thus making them less lucrative for investment.

Surprisingly, in the US market (the only Type 4 market) both the idiosyncratic and integrated idiosyncratic risks tend to produce extreme returns, as both risks induce momentum effects to drive the return away from zero in both directions. Thus these two risks enlarge the fluctuations in REIT returns. This suggests that the US market seems not to be a beneficial choice for the risk-averse investor whose investing strategy relies on risk control and investment diversification.

A study by Ang, Hodrick, Xing, and Zhang (2006) suggests that individual stocks of a high idiosyncratic volatility always lead to low average future returns in the US stock market. This section examines, for the first time, whether this phenomenon applies to (i) the US REIT market and (ii) global markets. The phenomenon can be translated into the condition $c_{i}^{\prime}<0$ in the asymmetric model. A negative coefficient indicates that idiosyncratic volatility is more likely to hinder positive returns and thus the average return will fall. The result in Table 4 provides weak support for the argument for the US market because $c^{\prime}>0$ for this market. However, the condition $c_{i}^{\prime}<0$ is satisfied for five markets: France, Hong Kong, Japan, the Netherlands and Singapore, where a higher idiosyncratic risk is more likely to produce a lower return.

\section{Conclusions}

This paper investigates the effects of idiosyncratic risk and its spillover in global REIT markets. The latter is measured by integrated idiosyncratic risk, which indicates the average spillover effect of idiosyncratic risk from other markets on REIT market return. A risk-return model is derived from GARCH-M to capture the correlations of idiosyncratic risk and the spillover effect of idiosyncratic risk to market return. The standard risk-return model is extended to an asymmetric model to reveal the asymmetry in the responses of volatility to the returns in a given market. The empirical study covers 10 major REIT markets around the world from 2001 to 2014. The major findings are summarized as follows.

(1) Integrated idiosyncratic risk plays a key role as it accounts for a major proportion of the total variance for most of the study period (2001-2014). The level of integrated idiosyncratic risk and the total variance gradually increased from 2007, reached their peaks in 2008, and then dropped.

(2) The risk-return model performs better than the GARCH-M model in some periods for most of the markets. In general, idiosyncratic risk always has the opposite effect to spillovers. Integrated idiosyncratic risk continues to exert impacts on market return in Australia, Japan, Singapore and the UK. These four markets are typical representatives, as many REITs pursue internationally investing strategies.

As the financial crisis spread across the world, the spillover of idiosyncratic risk substantially affected the REIT returns in all of the markets except for Hong Kong. In particular during the crisis, the spillover effects show stronger explanatory power than idiosyncratic risk for market return in Australia, Canada, France, Japan, the Netherlands, Singapore and the UK. In particular, the US market was affected by idiosyncratic risk and spillover effects by turns during the crisis. The idiosyncratic risk dragged the market down and drove the recession while the spillover effect tried to slow the recession.

A downward trend in the coefficient of idiosyncratic risk was found in the US market as well as in other markets before 2008. The finding regarding the US market is consistent with the findings in Liow and Addae-Dapaah (2010). However, this study provides a new finding, which is that there was a rebound of this coefficient in the US market after 2008. Meanwhile, the magnitude of idiosyncratic risk exceeds that of the spillover of idiosyncratic risk.

(3) Although the standard risk-return model is relatively suitable to characterize the return dynamics most of the time, the asymmetric model fits the data better for the crisis period in four markets: Australia, Belgium, Hong Kong and the US. Japan had the longest period of asymmetry in volatility before the crisis and the market return was fuelled by the idiosyncratic risk. This is mainly due to the long recession that affected Japan's economy from 1990. Moreover, the results suggest that if the previous returns are negative, idiosyncratic risk always has a mean reversing effect on the current returns, while the spillover effect always has a momentum effect on the current returns.

Furthermore, nine markets (except for the UK) can be categorized into four types in terms of asymmetric patterns. Type 1 market, which in this study includes only 
the Netherlands, are the most preferred markets in terms of acquiring excess return in periods with significant asymmetry. This may be due to their relatively low correlation with other markets: the Netherlands has been less affected by the financial crisis. On the other hand, the US is the least attractive market for risk-averse investors because both the idiosyncratic risk and the spillover tend to generate extreme returns. Both risks exhibit momentum effects, which drive REIT returns far away from zero in either direction. This reveals that the global financial crisis in 2008, which originated in the US, has made the US a much riskier market than before.

(4) We examine whether high idiosyncratic volatility would lead to a low average future return in global REIT markets (c.f. Ang et al., 2006). The findings suggest that the phenomenon exists in the US REIT market. Idiosyncratic risk proves a driving force in forming a series of negative returns. In France, Hong Kong, Japan, the Netherlands and Singapore, a higher idiosyncratic risk is more likely to produce a lower market return. This gives a better understanding of the role of idiosyncratic risk in REIT markets.

Compared with previous studies, this study offers a better understanding of the two different roles of idiosyncratic risk in the short term dynamics of REIT returns in the global markets. This paper also provides insights into the asset pricing implications of idiosyncratic risk, which not only benefits market participants in risk management and portfolio diversification, but also assists the relevant authorities in market monitoring and policymaking. The method introduced in this paper can be applied to other types of markets to test the role of idiosyncratic risk and spillover effects in the return mechanism.

\section{Acknowledgments}

The research was funded by the Polytechnic University's Internal Grants (G-UA3D, G-YBQ8 and G-YBUL). The authors are grateful to the editor and anonymous reviewers for their help and comments.

\section{References}

Ang, A., Hodrick, R. J., Xing, Y., \& Zhang, X. (2006). The crosssection of volatility and expected returns. Journal of Finance, 51, 259-299. https://doi.org/10.1111/j.1540-6261.2006.00836.x

Bali, T. G., \& Peng, L. (2006). Is there a risk-return trade-off? Evidence from high-frequency data. Journal of Applied Econometrics, 21, 1169-1198. https://doi.org/10.1002/jae.911

Bollerslev, T. (1986). Generalized autoregressive conditional heteroscedasticity. Journal of Econometrics, 31, 307-327. https://doi.org/10.1016/0304-4076(86)90063-1

Bond, S. A., Karolyi, G. A., \& Sanders, A. B. (2003). International real estate returns: a multifactor, multicountry approach. Real Estate Economics, 31(3), 481-500. https://doi.org/10.1111/1540-6229.00074

Campbell, J. Y., Lettau, M., Malkiel, B. G., \& Xu, Y. (2001). Have individual stocks become more volatile? An empirical exploration of idiosyncratic risk. Journal of Finance, 56, 1-43. https://doi.org/10.1111/0022-1082.00318
Case, B., Goetzmann, W. N., \& Rouwenhorst, K. G. (2000). Global real estate markets-cycles and fundamentals (No. w7566). National Bureau of Economic Research. https://doi.org/10.3386/w7566

Chaudhry, M., Maheshwari, S., \& Webb, J. (2004). REITs and idiosyncratic risk. Journal of Real Estate Research, 26(2), 207-222.

Chen, J., \& Peiser, R. (1999). The risk and return characteristics of REITs: 1993-1997. Real Estate Finance, 16(1), 61-68.

Chiang, K. C. H. (2010). On the comovement of REIT prices. Journal of Real Estate Research, 32(2), 187-200.

Clayton, J., \& MacKinnon, G. (2003). The relative importance of stock, bond and real estate factors in explaining REIT returns. Journal of Real Estate Finance and Economics, 27(1), 39-60. https://doi.org/10.1023/A:1023607412927

Cotter, J., \& Stevenson, S. (2006). Multivariate modeling of daily REIT volatility. Journal of Real Estate Finance and Economics, 32(3), 305-325. https://doi.org/10.1007/s11146-006-6804-9

Eichholtz, P. M. A. (1996). Does international diversification work better for real estate than for stocks and bonds?. Financial Analyst Journal, 52, 56-62. https://doi.org/10.2469/faj.v52.n1.1967

Engle, R. F. (1982). Autoregressive conditional heteroscedasticity with estimates of the variance of United Kingdom inflation. Econometrica, 50, 987-1007. https://doi.org/10.2307/1912773

Engle, R. F., Lilien, D. M., \& Robins, R. P. (1987). Estimating time varying risk premia in the term structure: the Arch-M model. Econometrica, 55, 391-407. https://doi.org/10.2307/1913242

$\mathrm{Fu}, \mathrm{F}$. (2009). Idiosyncratic risk and the cross-section of expected stock returns. Journal of Financial Economics, 91, 24-37. https://doi.org/10.1016/j.jfineco.2008.02.003

Goyal, A., \& Santa-Clara, P. (2003). Idiosyncratic risk matters! Journal of Finance, 58, 975-1007. https://doi.org/10.1111/1540-6261.00555

Hoesli, M., \& Reka, K. (2013). Volatility spillovers, comovements and contagion in securitized real estate markets. Journal of Real Estate Finance and Economics, 47(1), 1-35. https://doi.org/10.1007/s11146-011-9346-8

Hui, E. C. M., \& Wang, Z. (2014). Risk and credit change in Asian securitized real estate market. Habitat International, 43, 221-230. https://doi.org/10.1016/j.habitatint.2014.03.008

Hung, S. K., \& Glascock, J. (2010). Volatilities and momentum returns in real estate investment trusts. Journal of Real Estate Finance and Economics, 41, 126-149. https://doi.org/10.1007/s11146-008-9165-8

Liow, K. H., \& Addae-Dapaah, K. (2010). Idiosyncratic risk, market risk and correlation dynamics in the US real estate investment trusts. Journal of Housing Economics, 19, 205-218. https://doi.org/10.1016/j.jhe.2010.06.001

Liow, K. H., Chen, Z., \& Liu, J. (2011). Multiple regimes and volatility transmission in securitized real estate markets. Journal of Real Estate Finance and Economics, 42, 295-328. https://doi.org/10.1007/s11146-009-9200-4

Liow, K. H., Ho, K. H. D., Ibrahim, M. F., \& Chen, Z. (2009). Correlation and volatility dynamics in international real estate securities markets. Journal of Real Estate Finance and Economics, 39(2), 202-223. https://doi.org/10.1007/s11146-008-9108-4

Liow, K. H., \& Ibrahim, M. F. (2010). Volatility decomposition and correlation in international securitized real estate markets. Journal of Real Estate Finance and Economics, 40, 221243. https://doi.org/10.1007/s11146-008-9131-5

Martens, M., \& Poon. S. (2001). Returns synchronization and daily correlation dynamics between international stock markets. Journal of Banking and Finance, 25, 1805-1827. https://doi.org/10.1016/S0378-4266(00)00159-X 
Michayluk, D., Wilson, P. J., \& Zurbruegg, R. (2006). Asymmetric volatility, correlation and returns dynamics between the U.S. and U.K. securitized real estate markets. Real Estate Economics, 34, 109-131.

https://doi.org/10.1111/j.1540-6229.2006.00161.x

Nneji, O., Brooks, C., \& Ward, C. (2013). Commercial real estate and equity market bubbles: are they contagious to REITs? Urban Studies, 50(12), 2496-2516. https://doi.org/10.1177/0042098013477700

Ooi, J. T. L., Webb, J. R., \& Wang, J. (2009). Idiosyncratic risk and REIT returns. Journal of Real Estate Finance and Economics, 38, 27-55. https://doi.org/10.1007/s11146-007-9091-1

Pagliari, J. L., Scherer, K. A., \& Monopoli, R. T. (2003). Public versus private real estate equities. Journal of Portfolio Management, 29, 101-111. https://doi.org/10.3905/jpm.2003.319911
Payne, J. M., \& Waters, G. A. (2007). Have equity REITs experienced periodically collapsing bubbles. Journal of Real Estate Finance and Economics, 34, 207-224. https://doi.org/10.1007/s11146-007-9007-0

Sagalyn, L. (1990). Real estate risk and the business cycle: evidence from security markets. Journal of Real Estate Research, 5(2), 203-219.

Stevenson, S. (2002). An examination of volatility spillovers in REIT returns. Journal of Real Estate Portfolio Management, $8(3), 229-238$

Worzala, E., \& Sirmans, C. F. (2003). Investing in international real estate stocks: a review of the literature. Urban Studies, 40(5-6), 1115-1149. https://doi.org/10.1080/0042098032000074344

Xu, Y., \& Malkiel, B. G. (2003). Investigating the behaviour of idiosyncratic volatility. Journal of Business, 76, 613-64. https://doi.org/10.1086/377033 